\title{
ORIGINAL ARTICLE \\ Complications and urologic risks of neurogenic bladder in veterans with traumatic spinal cord injury
}

\author{
MH Rabadi ${ }^{1}$ and C Aston ${ }^{2}$
}

Objectives: This observational study aimed to determine the types of urological lesion encountered in veterans with traumatic spinal cord injury (SCI) with neurogenic bladder (NGB), and the usage of bladder management programs to deal with NGB.

Setting: NGB (detrusor muscle and urethral sphincter dysfunction with loss of bladder sensation to void) is common in daily practice; however, information on types of urological lesions encountered in these veterans with NGB and how best to manage their NGB is limited.

Methods: We retrospectively reviewed the electronic charts of veterans with SCl enrolled in our program and regularly followed in our $\mathrm{SCl}$ clinic. Demographic data collected included: age, gender, ethnicity and age, level, severity and cause of spinal injury. Also noted was presence of NGB, episodes of urinary tract infection (UTI), bladder program followed and urological lesions found on renal nuclear scans, renal ultrasounds and cystoscopies.

Results: Of the 161 veterans with SCl, symptoms of NGB was present in $133(82.6 \%)$. Veterans with NGB had more severe spinal injury and more frequent UTI $(P<0.05)$. Renal atrophy and hydronephrosis were the most common urological lesions seen in patients with UTI. Clean intermittent catheterization $(\mathrm{CIC})$ was the most frequently used bladder program resulting in less frequent occurrence of UTI.

Conclusion: Renal atrophy and hydronephrosis were the most common urological lesions encountered in veterans with NGB especially in those with UTI. CIC was the most frequently used bladder management program with the least risk for UTI.

Spinal Cord (2015) 53, 200-203; doi:10.1038/sc.2014.205; published online 18 November 2014

\section{INTRODUCTION}

Detrusor muscle and urethral sphincter dysfunction with loss of bladder sensation to void due to spinal cord injury (SCI) results in a neurogenic bladder (NGB). ${ }^{1}$ The main types of NGB are: (a) Failure to store urine from a hyperreflexic detrusor or a decrease in sphincter resistance, (b) failure to empty urine from a areflexic detrusor or an increase in sphincter resistance or (c) detrusor sphincter dyssynergia from lack of co-ordination between detrusor contraction and sphincter relaxation leading to high voiding pressure and incomplete emptying. $^{2}$

Commonly encountered urological lesions have been bladder stones but other lesions such as renal stones, urethral fistulas, erosions, stricture and infections, such as cystitis and epididymitis, have resulted mainly from how the NGB is managed., ${ }^{3,4}$

Management of NGB usually entails ensuring an adequate fluid intake to maintain a urine flow of 1.5-2.0 liters per day. Options include clean intermittent catheterization (CIC), use of external (condom), indwelling (Foley) or supra-pubic catheters where indicated, ${ }^{5}$ and good personal hygiene including replacement of Foley and supra-pubic catheters and urinary containment devices every 28 days. Since the initial recommendation by Guttman et al. ${ }^{6}$ and Lapides et al. ${ }^{7}$ to use CIC for bladder management in patients with SCI, CIC is now the practice method preferred by $84 \%$ of 269 certified urologists surveyed by mail questionnaire. ${ }^{8}$ Physicians taking care of
SCI patients should be aware of the recent guidelines on how best to manage patients with NGB. ${ }^{9}$

We therefore decided to study the management of NGB and the types of renal and urological lesions commonly encountered in veterans with SCI who are regularly followed in our SCI program on an outpatient basis. The findings of this study will help improve our bladder management program in these patients to reduce risk of renal and urological lesions and in turn improve their quality of life.

\section{PATIENTS AND METHODS \\ Participants}

The local Institutional Review Board for Human Subjects Research and the local Veterans Affairs Research and Development Committees' approval were obtained for the study. On retrospective chart review there were 161 veterans with SCI registered in our SCI program at the Oklahoma City VA Medical Center from 1 January 2000 through 12 December 2012, who were routinely seen every 4 months. All patients with SCI seen in the clinic during this time frame were included. Veterans with SCI are usually enrolled in our program within a year of their injury. The average follow-up time of these patients within the study period was $10.5 \pm 3.8$ (s.d.) years. During clinic visits patients were assessed for current medical conditions such as autonomic dysreflexia, urinary tract infection (UTI) and spasticity. Self-care strategies for managing their neurogenic bowel and bladder and pressure ulcer prevention were also reviewed. Data collected from chart review included age at the time of injury, gender, ethnicity, level and severity of injury based on the American Spinal Injury Association Impairment Scale (grade: A, B, C, D and E), ${ }^{10}$ etiology

${ }^{1}$ Department of Neurology at Oklahoma University and Oklahoma City Veterans Affairs Medical Center, Oklahoma City, OK, USA and ${ }^{2}$ Department of Pediatrics, Oklahoma Health Sciences Center, Oklahoma City, OK, USA

Correspondence: Dr MH Rabadi, Oklahoma City Veterans Affairs Medical Center, 921 NE 13th Street, Oklahoma City, OK 73104, USA.

E-mail: rabadimh@gmail.com

Received 29 May 2014; revised 17 October 2014; accepted 20 October 2014; published online 18 November 2014 
(motor vehicle crash, gunshot wound, fall, diving or other), age at onset of SCI, time since onset of the SCI and SCI-related complications such as neurogenic bowel and bladder on their initial evaluation and subsequent follow-up visits by a certified clinician.

Veterans Health Administation directive stipulates that veterans with SCI and NGB should have a bladder management program based on the specific bladder dysfunction found on the initial urodynamic study once clinically stable after their initial injury. These veterans should on each follow-up visit be tested for blood urea nitrogen, creatinine, glomerular filtration rate and urinary

Table 1a Urological lesions relative to the level of traumatic spinal cord injury lesion (mean \pm s.d., or $n(\%)$, as appropriate)

\begin{tabular}{|c|c|c|c|c|}
\hline Tests & $\begin{array}{l}\text { Cervical } \\
(\mathrm{n}=86)\end{array}$ & $\begin{array}{l}\text { Thoracic } \\
(n=50)\end{array}$ & $\begin{array}{l}\text { Lumbosacral } \\
\qquad(\mathrm{n}=21)\end{array}$ & $\mathrm{P}$-value \\
\hline \multicolumn{5}{|l|}{ Blood tests } \\
\hline Blood urea nitrogen & $19 \pm 19$ & $18 \pm 20$ & $15 \pm 8$ & 0.62 \\
\hline Creatinine & $1.0 \pm 0.8$ & $1.1 \pm 1.1$ & $1.2 \pm 1.4$ & 0.73 \\
\hline $\begin{array}{l}\text { Estimated glomerular } \\
\text { filtration rate (eGFR) }\end{array}$ & $108 \pm 39$ & $103 \pm 34$ & $90 \pm 30$ & 0.48 \\
\hline $\begin{array}{l}\text { Glomerular filtration } \\
\text { rate (GFR) }\end{array}$ & $76 \pm 31$ & $91 \pm 31$ & $96 \pm 36$ & 0.052 \\
\hline Renal ultrasound & $n=64$ & $n=42$ & $n=13$ & \\
\hline Renal atrophy & $6(9.4)$ & 5 (11.9) & $1(7.7)$ & 0.87 \\
\hline Simple renal cysts & $15(23.4)$ & $8(19)$ & $3(23.1)$ & 0.86 \\
\hline Renal calculi & $11(17.2)$ & $3(7.1)$ & $1(7.7)$ & 0.27 \\
\hline Hydronephrosis & $7.0(8.0)$ & $1(1.9)$ & $1(4.8)$ & 0.27 \\
\hline Cystoscopy & $n=13$ & $n=7$ & $n=3$ & \\
\hline $\begin{array}{l}\text { Urinary bladder } \\
\text { calculi }\end{array}$ & $5(38.5)$ & $1(14.3)$ & $2(66.7)$ & 0.26 \\
\hline $\begin{array}{l}\text { Urinary bladder } \\
\text { thickening }\end{array}$ & $1(7.7)$ & $0(0)$ & $1(33.3)$ & 0.23 \\
\hline $\begin{array}{l}\text { Urinary tract } \\
\text { infection }\end{array}$ & $35(39.8)$ & $24(46.2)$ & $3(14.3)$ & 0.038 \\
\hline Pressure ulcers & $27(30.7)$ & $20(38.5)$ & $3(14.3)$ & 0.31 \\
\hline
\end{tabular}

Statistically significant values are indicated in bold. analysis. They should have a yearly renal ultrasound to evaluate renal structure, a radionuclide renal scan to evaluate both structure and function by measuring glomerular filtration rate, a urology consult for cystoscopy to evaluate bladder structure and urodynamic study to evaluate bladder function when needed. Though the bladder management is driven by the urodynamic study findings, it is modified by the veteran's preference, his personal setup and change in the level of AIS severity overtime. Presence of UTI was defined by a urine analysis showing presence of significant bacteriuria $\left(\geqslant 10^{5} \mathrm{cfu} \mathrm{ml}^{-1}\right)$ in the presence of nitrites and white blood cells $>10$ per high power field, and a positive urine culture, with or without symptoms or signs such as fever $\left(>100^{\circ} \mathrm{F}\right)$, chills, lethargy, increasing muscle spasms, Autonomic Dysreflexia, malodorous and cloudy urine, lower abdominal pain/tenderness provided no other potential etiology for these nonspecific complains were identified. Antibiotics were prescribed based on urine culture and sensitivity findings.

\section{Statistical analysis}

Group-descriptive statistics were expressed as mean \pm s.d. and grouped frequencies. Differences between groups were assessed using the Generalized Linear Model framework. In the simplest case of two-group comparisons without covariates this is equivalent to using $t$-tests for continuous variables and $\chi^{2}$ for categorical data, but allows generalization to include covariates in the model. Covariates considered were age at the time of injury, severity of injury (AIS grade) and duration since SCI. Data analyses were conducted using IBM SPSS Statistics (IBM Corp. Released 2011. IBM SPSS Statistics for Windows, Version 20.0. Armonk, NY, USA). Results corresponding to $P$-values lower than $5 \%$ are described as significant and reported.

\section{RESULTS}

The mean age of our study sample $(n=161)$ was $59.5 \pm 13.6$ years (range 25-90 years), male:female ratio was 157:4, 80.7\% were nonhispanic white, age at onset of injury was $38.8 \pm 16.6$ years (range 1882 years) and duration since SCI insult $20.6 \pm 16.6$ years (range 1-68 years). The most common cause of injury in $47 \%$ was motor vehicle/ cycle accident followed by falls in $29 \%$. The spinal level of injury was cervical in $55 \%$, thoracic in $32 \%$ and lumbosacral in $13 \%$. Severity of injury based on American Spinal Cord Injury Impairment scoring was: A $36 \%$, B $15.5 \%$, C $19.2 \%$, D 22.9 and E $6.2 \%$. Symptoms of NGB such as urinary incontinence were present in 133 of the 161 patients

Table 1b Urological lesions relative to the severity on the AIS grade (mean \pm s.d., or $n(\%)$, as appropriate)

\begin{tabular}{|c|c|c|c|c|c|c|}
\hline Tests & $A / S A(\mathrm{n}=58)$ & $A / S B(\mathrm{n}=25)$ & $A / S C(\mathrm{n}=31)$ & $A / S D(\mathrm{n}=37)$ & AIS $E(\mathrm{n}=10)$ & P-value \\
\hline \multicolumn{7}{|l|}{ Blood tests } \\
\hline Blood urea nitrogen & $20 \pm 23$ & $21 \pm 26$ & $14 \pm 5$ & $20 \pm 12$ & $14 \pm 7$ & 0.48 \\
\hline Creatinine & $1.0 \pm 1.1$ & $1.0 \pm 0.7$ & $0.9 \pm 0.2$ & $1.5 \pm 1.4$ & $1.0 \pm 0.3$ & 0.13 \\
\hline Estimated glomerular filtration rate & $119 \pm 46$ & $118 \pm 21$ & $86 \pm 19$ & $85 \pm 25$ & \pm & 0.011 \\
\hline Glomerular filtration rate & $82 \pm 34$ & $87 \pm 30$ & $81 \pm 32$ & $87 \pm 31$ & $100 \pm 60$ & 0.88 \\
\hline Renal ultrasound & $n=48$ & $n=22$ & $n=22$ & $n=25$ & $n=2$ & \\
\hline Renal atrophy & $6(12.5)$ & $4(18.2)$ & $0(0)$ & $1(4)$ & $1(50)$ & 0.064 \\
\hline Simple renal cysts & $10(20.8)$ & $8(36.4)$ & $6(27.3)$ & $2(8)$ & $0(0)$ & 0.17 \\
\hline Renal calculi & $5(10.4)$ & $3(13.6)$ & $4(18.2)$ & $3(12)$ & $0(0)$ & 0.89 \\
\hline Hydronephrosis & $5(10.4)$ & $3(13.6)$ & $0(0)$ & $1(4)$ & $0(0)$ & 0.39 \\
\hline Cystoscopy & $n=12$ & $n=6$ & $n=3$ & $n=1$ & $n=1$ & \\
\hline Urinary bladder calculi & $5(41.7)$ & $1(16.7)$ & $1(33.3)$ & $1(100)$ & $0(0)$ & 0.47 \\
\hline Urinary bladder thickening & $0(0)$ & $1(16.7)$ & $0(0)$ & $0(0)$ & $1(100)$ & 0.014 \\
\hline Urinary tract infection & $32(55.2)$ & $14(56)$ & $9(29)$ & $6(16.2)$ & $1(10)$ & 0.0002 \\
\hline Pressure ulcers & $33(56.9)$ & $12(48)$ & $5(16.1)$ & $0(0)$ & $0(0)$ & 0.31 \\
\hline
\end{tabular}

Abbreviation: AIS, American Spinal Injury Association (ASIA) Impairment Scale.

Statistically significant values are indicated in bold. 
with SCI, giving a prevalence of $82.6 \%$ during the 13 -year-study period.

Of the 161 patients, 119 had a renal ultrasound (Tables 1a and b). The urological lesions found were renal atrophy $(10 \%)$, simple renal cysts $(22 \%)$, renal calculi (13\%) and hydronephrosis (8\%). Only 23 patients had cystoscopy, these found urinary bladder calculi $(22 \%)$ and urinary bladder wall thickening (4\%). The distributions of urological lesions based on renal ultrasound and cystoscopies did not differ significantly across different levels of spinal injury $(P>0.05)$. However, lower glomerular filtration rate by renal scan and more frequent UTI episodes were seen in cases with a cervical level of injury $(P<0.05)$. Similarly, the distribution of urological lesions based on

Table 2a Relationship of bladder program to the level of traumatic spinal cord injury lesion ( $\boldsymbol{n}(\%)$, as appropriate)

\begin{tabular}{|c|c|c|c|c|c|}
\hline Bladder program & $\mathrm{n}$ & $\begin{array}{l}\text { Cervical } \\
(\mathrm{n}=88)\end{array}$ & $\begin{array}{l}\text { Thoracic } \\
(\mathrm{n}=52)\end{array}$ & $\begin{array}{l}\text { Lumbosacral } \\
\qquad(\mathrm{n}=21)\end{array}$ & P-value \\
\hline $\begin{array}{l}\text { None-spontaneous } \\
\text { voiding }\end{array}$ & 45 & $30(34.1)$ & $9(17.3)$ & $6(28.6)$ & 0.048 \\
\hline $\begin{array}{l}\text { Clean intermittent } \\
\text { catheterization }\end{array}$ & 40 & $15(17)$ & $15(28.8)$ & $10(47.6)$ & \\
\hline Condom & 9 & $3(3.4)$ & $5(9.6)$ & $1(4.8)$ & \\
\hline Foley catheter & 27 & $13(14.8)$ & $14(26.9)$ & $0(0)$ & \\
\hline Supra-pubic & 22 & 14 (15.9) & 7 (13.5) & $1(4.8)$ & \\
\hline Timed voiding & 2 & $2(2.3)$ & $0(0)$ & $0(0)$ & \\
\hline Urostomy & 7 & $5(5.7)$ & $1(1.9)$ & $1(4.8)$ & \\
\hline Ileostomy & 1 & $1(1.1)$ & $0(0)$ & $0(0)$ & \\
\hline
\end{tabular}

Statistically significant values are indicated in bold. renal ultrasound and cystoscopy did not differ significantly across all grades of severity $(P>0.05)$. However, higher glomerular filtration rate on blood testing and more frequent UTI episodes were seen in more severe injury grades, AIS A or B $(P<0.05)$. Patients with UTI had more frequent urological lesions such as renal atrophy $(18 \%)$ and hydronephrosis $(12 \%)$ compared with those without UTI $(3 \%$ and $3 \%$, respectively, $P<0.05)$.

Urinary bladder management program was documented in 153 patients (95\%) (Tables 2a-c). The most frequently used bladder program was: none (spontaneous voiding) in 45 cases (29\%), followed by CIC in $40(26 \%)$, Foley catheter in $27(18 \%)$ and supra-pubic in 22 (14\%). Spontaneous voiding and CIC were more commonly used in SCI affecting the lumbosacral level, whereas Foley and supra-pubic catheterizations were more commonly used in SCI affecting cervical and thoracic level $(P<0.05)$. Similarly, spontaneous voiding and CIC was more commonly used in patients with incomplete motor SCI (AIS $\mathrm{D}$ or E), whereas Foley and supra-pubic catheterizations were more common in patients with complete SCI (AIS A or B) $(P<0.05)$.

\section{DISCUSSION}

Given that the consequences of NGB are preventable, ${ }^{5}$ Veterans Health Administration directive 1176 stipulates all eligible veterans with Spinal Cord Injury and Disorder (SCI\&D) be provided with a full range of care to promote and maintain health, independence and quality of life so they can be productive individuals.

In this retrospective longitudinal study, the most common urological lesions encountered on renal scan were: renal atrophy, calculi, simple renal cyst and hydronephrosis; and on cystoscopy was bladder calculi and bladder wall thickening. Presence of a particular type of urological lesions had no relation to the level or severity of spinal cord

Table $2 \mathrm{~b}$ Relationship of bladder program to the severity on AIS grade ( $n(\%)$, as appropriate)

\begin{tabular}{|c|c|c|c|c|c|c|}
\hline Bladder program & $A / S A(\mathrm{n}=58)$ & $A / S B(\mathrm{n}=25)$ & $A I S C(\mathrm{n}=31)$ & $A I S D(\mathrm{n}=37)$ & AIS $E(\mathrm{n}=10)$ & P-value \\
\hline None-spontaneous voiding & $4(6.9)$ & $3(12)$ & $8(25.8)$ & $22(59.5)$ & $8(80)$ & 0.0000 \\
\hline Clean intermittent catheterization & $10(17.2)$ & $7(28)$ & $13(41.9)$ & $9(24.3)$ & $1(10)$ & \\
\hline Condom & $3(5.2)$ & $4(16)$ & $1(3.2)$ & $0(0)$ & $1(10)$ & \\
\hline Foley catheter & $17(29.3)$ & $4(16)$ & $4(12.9)$ & $2(5.4)$ & $0(0)$ & \\
\hline Supra-pubic & $16(27.6)$ & $5(20)$ & $1(3.2)$ & $0(0)$ & $0(0)$ & \\
\hline Timed voiding & $0(0)$ & $0(0)$ & $0(0)$ & $2(5.4)$ & $0(0)$ & \\
\hline Urostomy & $5(8.6)$ & $2(8.0)$ & $0(0)$ & $0(0)$ & $0(0)$ & \\
\hline Ileostomy & $1(1.7)$ & $0(0)$ & $0(0)$ & $0(0)$ & $0(0)$ & \\
\hline
\end{tabular}

Abbreviation: AIS, American Spinal Injury Association (ASIA) Impairment Scale.

Statistically significant values are indicated in bold.

Table 2c Relationship of bladder program to neurogenic bladder management and its findings

\begin{tabular}{|c|c|c|c|c|c|c|c|c|}
\hline \multirow[t]{2}{*}{ Bladder program } & \multirow[t]{2}{*}{$\mathrm{n}$} & \multirow[t]{2}{*}{ Urinary tract infection } & \multicolumn{4}{|c|}{ Renal ultrasound } & \multirow[t]{2}{*}{ Cystoscopy } & \multirow[t]{2}{*}{ Urodynamics } \\
\hline & & & Renal atrophy & Simple renal cyst & Renal calculi & Hydronephrosis & & \\
\hline None-spontaneous voiding & 45 & $7(15.6)$ & $2(7.4)$ & $7(25.9)$ & $6(22.2)$ & $0(0)$ & $1(33.3)$ & $0(0)$ \\
\hline Clean intermittent catheterization & 40 & $14(35)$ & $0(0)$ & 7 (21.9) & $2(6.2)$ & $2(6.3)$ & $2(6.3)$ & $0(0)$ \\
\hline Condom & 9 & $4(44.4)$ & $2(25)$ & $2(25)$ & $4(50)$ & $2(25)$ & $0(0)$ & $1(50)$ \\
\hline Foley catheter & 27 & $13(48.1)$ & $3(13.6)$ & $2(9.1)$ & $0(0)$ & $1(4.5)$ & $1(25)$ & $1(25)$ \\
\hline Supra-pubic & 22 & $16(72.7)$ & $3(15)$ & $5(25)$ & $1(5)$ & $2(10)$ & $2(40 \%)$ & $0(0)$ \\
\hline Timed voiding & 2 & $0(0)$ & $0(0)$ & $0(0)$ & $0(0)$ & $0(0)$ & $0(0)$ & $0(0)$ \\
\hline Urostomy & 7 & 7 (100) & $2(28.6)$ & $2(28.6)$ & $2(28.6)$ & $2(28.6)$ & $2(50)$ & $0(0)$ \\
\hline Ileostomy & 1 & $1(100)$ & $0(0)$ & $1(100)$ & $0(0)$ & $0(0)$ & $0(0)$ & $0(0)$ \\
\hline
\end{tabular}


injury. We had a low uptake of cystoscopy and urodynamic studies in this study (16\%) as the veterans refused to undergo invasive urological testing. Similar low levels of diagnostic testing were found by Chen et al. in their study of 1649 patients in 18 Modular Spinal Cord Injury Services. They also found that abnormal test results were not associated with patient age, level of injury, or severity of injury. ${ }^{11}$

The aim of bladder management program is to reduce the incidence of urological lesions, UTI and preserve renal function. In this study spontaneous voiding followed by CIC was the most frequent bladder management program over a 13-year-period. Condom catheters were used by $6 \%$ of the veterans who were able to spontaneously void but used it at night time as they had difficulty getting-up and making it to the toilet in time and by those veterans who used it for long road trips. Thirty-two percent of the patients had indwelling catheters, compared with $47 \%$ in the Weld and Dmochowski ${ }^{12}$ study of 316 veterans with SCI. Weld and Dmochowski found normal bladder compliance on urodynamic studies to be the highest in CIC (73.9\%) and lowest in the Foley catheter $(23.3 \%)$ groups. The type of bladder program was strongly influenced by both the level (Table 2a) and severity of injury (Table 2b) in this study. Patients with lumbosacral injury were able to self-void or use CIC in 76\% cases, whereas patients with cervical and thoracic injury needed Foley or supra-pubic catheterization. Likewise, spontaneous voiding occurred in $60-80 \%$ of the patients with AIS grade D or E, CIC in $42 \%$ of patients with AIS grade C and Foley and supra-pubic catheterization by patients with AIS grade A or B. McKinley et al., in their study of patients enrolled in Modular Spinal Cord Injury Services, found indwelling catheters were more frequently used by those who were tetraplegic-complete than by those who were paraplegic-incomplete. ${ }^{13,14}$

In our study UTI was present in 16 and $35 \%$ of the cases of spontaneous voiding and CIC compared with $48 \%$ in the indwelling Foley and $73 \%$ in the supra-pubic catheter groups. Although the frequency of UTI was lower in the CIC group compared with the indwelling catheter group the frequency of UTI was still high compared with other studies and had to do with poor CIC technique in our patients. Renal stones on renal ultrasound were found in 6,0 and $5 \%$ of the cases in the CIC, indwelling Foley and supra-pubic catheter groups, respectively. Larsen et $a l^{4}$, in their study of 142 veterans with SCI, found the CIC group to have fewer incidences of UTI, renal calculi, urethral strictures and tears and bladder cancer compared with the catheterized group. Likewise, Weld et al. ${ }^{15}$ found urological complications in $53.5 \%$ of patients with chronic indwelling catheters versus $27.2 \%$ in the CIC group. Chen et al., in their study of 8314 patients with SCI enrolled in Modular Spinal Cord Injury Services Care program, found bladder management program had no effect on renal stone formation. They found most of their first kidney stones (7\%) were acquired within the initial 10 years of injury, and was strongly associated with bladder instrumentation ${ }^{3}$ as was the case in our study.

There are several limitations of this study: first, this study was limited to a veteran population predominantly comprised of white men, so it may not be generalizable to the general population; second, the small sample size may preclude determining of some differences between groups as significant; third, this was a single center study; fourth, the inherent bias associated with the retrospective data should be considered. However, the strength of this study lies in the completeness of the data captured by the standardized SCI registry over a 13-year-period with no patient lost to follow-up.

\section{CONCLUSION}

This study shows that the urological lesions mainly encountered in veterans with NGB on renal scan were renal atrophy, renal calculi, simple renal cyst and hydronephrosis; and on cyctoscopy bladder calculi and bladder wall thickening; and CIC was the commonly used and a better bladder management method to deal with NGB as they had reduced incidence of UTI and needed less frequent hospitalization. Since the analysis of our data, we now have a regular bowel and bladder class where both the patient and their caregiver receive education, hands-on-training and demonstration of CIC skills on a mannequin and a hand-out, which reinforces the taught catheterization steps in the class to reduce the incidence of UTI.

\section{DATA ARCHIVING}

There were no data to deposit.

\section{CONFLICT OF INTEREST}

The authors declare no conflict of interest.

\section{ACKNOWLEDGEMENTS}

CEA was funded for this study by the National Institutes of Health, National Institute of General Medical Sciences, grant 1 U54GM104938.

1 Rackley R, Kim ED. Neurogenic bladder. Available on: http://emedicine.medscape.com/ article/453539-overview. Accessed on September 2012.

2 Wein AJ. Classification of neurogenic voiding dysfunction. J Urol 1981; 125 : 605-609.

3 Chen Y, DeVivo MJ, Roseman JM. Current trend and risk factors for kidney stones in persons with spinal cord injury: a longitudinal study. Spinal Cord 2000; 38: 346-353.

4 Larsen LD, Chamberlin DA, Khonsari F, Ahlering TE. Retrospective analysis of urologic complications in male patients with spinal cord injury managed with and without indwelling urinary catheters. Urology 1997; 50: 418-422.

5 Smith JM. Indwelling catheter management: from habit-based to evidence-based practice. Ostomy Wound Manage 2003; 49: 34-45.

6 Guttmann L, Frankel H. The value of intermittent catheterisation in the early management of traumatic paraplegia and tetraplegia. Paraplegia 1966; 4: 63-84.

7 Lapides J, Diokno AC, Silber SJ, Lowe BS. Clean, intermittent self-catheterization in the treatment of urinary tract disease. J Urol 1972; 107: 458-461.

8 Razdan S, Leboeuf L, Meinbach DS, Weinstein D, Gousse AE. Current practice patterns in the urologic surveillance and management of patients with spinal cord injury. Urology 2003; 61: 893-896.

9 Stöhrer M, Blok B, Castro-Diaz D, Chartier-Kastler E, Del Popolo G, Kramer G et al. EAU guidelines on neurogenic lower urinary tract dysfunction. Eur Urol 2009; 56: 81-88.

10 American Spinal Injury Association. Reference Manual of the International Standards for Neurological Classification of Spinal Cord Injury. American Spinal Injury Association: Chicago, IL, USA, 2003.

11 Chen D, Apple Jr DF, Hudson LM, Bode R. Medical complications during acute rehabilitation following spinal cord injury — current experience of the Model Systems. Arch Phys Med Rehabil 1999; 80: 1397-1401.

12 Weld KJ, Dmochowski RR. Effect of bladder management on urological complications in spinal cord injured patients. J Urol 2000; 163: 768-772.

13 Cameron AP, Wallner LP, Tate DG, Sarma AV, Rodriguez GM, Clemens JQ. Bladder management after spinal cord injury in the United States 1972 to 2005. J Urol 2010; 184: 213-217.

14 McKinley WO, Jackson AB, Cardenas DD, DeVivo MJ. Long-term medical complications after traumatic spinal cord injury: a regional model systems analysis. Arch Phys Med Rehabil 1999; 80: 1402-1410.

15 Weld KJ, Graney MJ, Dmochowski RR. Differences in bladder compliance with time and associations of bladder management with compliance in spinal cord injured patients. J Urol 2000; 163: 1228-1233. 